\title{
Linking Economic with Epidemiology: A Conceptual Approach of the Impact of Business Cycles on Animal Health and Human Health
}

\author{
Idqan Fahmi \\ School of Business \\ IPB University (Bogor Agricultural University) \\ Bogor, Indonesia \\ ifahmi.mk@gmail.com
}

\author{
Dikky Indrawan \\ School of Business \\ IPB University (Bogor Agricultural University) \\ Bogor, Indonesia \\ rdikky@apps.ipb.ac.id
}

\begin{abstract}
As economics recession leads to lower health status of the nation, linking economic with the epidemiology is needed to understand the economic activities concerning health and its effort to recover the economy. This paper proposed a conceptual approach as the reasoning foundation for further research on the government's decision to perform disease control and intervention that can support economic recovery. The general concept of micro-mezzomacroeconomics interaction was provided to be responsible for economic activities interaction. The expected results from the proposed approach show reasoning to support economic recovery.
\end{abstract}

Keywords - business cycle, epidemiology, outbreak, animal health, human health, classical economics, Keynesian economics

\section{INTRODUCTION}

In the history of the new emerging disease, it is known that economic behavior is one of the essential causes of disease transmission. A study from Perrings, et al. [1] describes that market, global trade, and travel routes are the main factor of disease outbreaks that affect the likelihood of pathogens spread. The factors also cause a variety of infectious-susceptible contacts. Perring study shows some key examples, such as the Black Death in the fourteenth century, smallpox and typhus to the Americas, syphilis to Europe, plague, cholera, HIV, West Nile virus, and SARS. The example of outbreaks to livestock diseases are such as H9N2 Avian influenza, Bovine Spongiform Encephalopathy, Bluetongue or Foot and Mouth disease. Likewise, the people's choices to take part in their community events and activities influence the spread of disease nationwide.

Since most studies believe that economic activity affects health, it is interesting to identify the reason behind economic activity that affects animal health and or human health. Furthermore, understanding the mechanism of economic or business cycle influence the animal and or human health will give appropriate public interventions to counterbalance the consequence of disease to the national and worldwide economy.

There is limited integrated analysis available about the impact of business cycle on animal health and human health. Limited information was provided on the link between economic with epidemiology. Due to this limited information, therefore, our article aims to describe the situation of business cycle and disease in the context of economic intervention. The objective was to propose a brief conceptual approach as a method to study the link between economic with epidemiology. As an interdisciplinary approach, the paper explains the influence of the business cycle on animal health and human health..

\section{MATERIALS AND METHODS}

In this paper, we collected and reviewed available literature related to the business cycle and health. Then, we systematically mapped the theory to provide a general concept as groundwork and a basic approach to the business cycle. We adapted and linked the theory of business cycle in the economic system with its impact on health in general. Then we specifically looked at the recession phase from the business cycle to determine its impact on one health perspective. Then we used the assumption of disease control as a strategy to recover the business cycle.

\section{GENERAL CONCEPT: MACRO-MEZZO-MICRO ECONOMICS, BUSINESS CYCLE, AND INTERVENTION}

An economic system is a complex construction of developed rules over a period of time. The development of initial rules to become an economic system sort out the evolved force of economic drivers. Economic drivers connect the different elements that were present both within and outside the system. Rules construct the corresponding relationships between elements in a range of network. The rule describes the relation between microeconomics elements to macroeconomics elements via mezzoeconomics elements. Therefore, the behavior of the economic system is best understood in the relations of micro-mezzo-macro [2].

In the economic system, the national economic behavior starts from microeconomics that describes a change in the composition and interaction of rule-carrier elements. The microeconomics can be seen as an aggregate unit based on a system of rule population as mezzo-economics. Furthermore, the system as a whole shows an interacting rule between the mezzo units, in which the element involves a change in the coordination structure as the aggregation of macroeconomics [2]. The change and interaction in macroeconomics are known as the aggregate moods of the economy. 
As macroeconomics is known as mood barometers, it shows the problems in the economics system. In general, economics barometers show the central problems of macroeconomics. The problems are as follows:

1. Growth: As an objective of every nation, the economy is always expected in the state of growing or expanding, which measured by real gross domestic product (GDP).

2. Unemployment: The unemployment rate is the main issue in economic growth. It shows the percentage of people in the nation who are keen and capable to work but not having a job.

3. Inflation: Inflation is the challenge faces by the nation since it shows a constant increase in the price level, which is measured by price indexes.

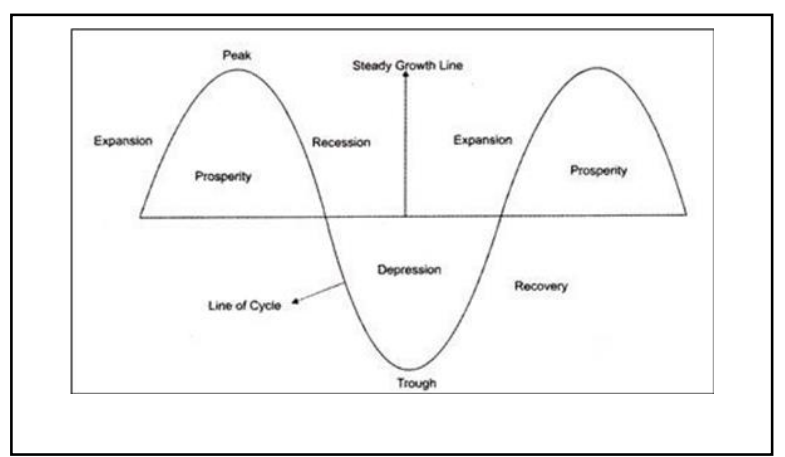

Fig. 1. The graphical representation of different phases of a business cycle.

The central problem of macroeconomics is depicted in the business cycle $[3,4]$. The cycle is the fluctuation movement of economic activity that takes place around the growth trend. Principally, there are two important phases in a business cycle called prosperity and depression. The other phases, as shown in Fig. 1, represent the growth of economy that moves upward and downward. The different phases of a business cycle are explained as follows:

1. Expansion: In this phase, various economic factors are increases simultaneously. This phase leads to an increase in investment opportunities toward favorable economic conditions.

2. Peak: In this phase, the expansion growth slows down and reaches its maximum limit. The economic factors reach the maximum level and are not able to increase further.

3. Recession: After the peak phase, a continuing decrease in the demand for various products becomes prompt and stable. The product supply exceeds the demand. Therefore, producers stop further investment as consequences in the decline of demand of inputs as well as output.

4. Trough: As the national economic activities are lower than the normal level. At this point, an economy shrinks to the lowest level. Therefore, many companies dissolve and leave businesses.

5. Recovery: After the trough phase, it will lead to a reversal of the business cycle. This phase marks the beginning of the recovery phase. It is shown by an increase in investment and employment by companies. Then this phase is expected as the foundation of economic momentum to reach the expansion phase.

Many experts see the business cycle as the consequences of an iterative equilibrium from very dynamic economic activities [4]. There are two perspectives in the monetary and fiscal approach with regard to the economic policy to countermeasure the business cycle. First, classical economics. There is a group of economists who mostly favor laissez-faire or noninterfering policies [5]. They claim that business cycles are to be expected in a market economy. Second, Keynesians economics. There is a group of economists who believe that fluctuations should be controlled. They are in favor of forward-looking policies [6, 7].

The differences between classical economy theory and Keynesian theory lie in the use of government policies, among other things [8]. The classical supporter thinks the business cycle in the economy is better to be left without help as it will regulate itself. On the contrary, the Keynesian supporter argues that government should play an active role in controlling the economy. The implications of both also have consequences for businesses in the making of strategic goals for their companies.

\section{THE RECESSION AND LONG-RUN EFFECT ON HEALTH: THE ONE HEALTH PERSPECTIVE}

In many cases of recession, many governments and citizens experience severe economic hardship across the world. Many studies prove that the financial crisis triggers the decrease of health and the rapid outbreak of infectious diseases [9]. Since the recession limits government capacity to control the health status and disease outbreak, and as a result, it increases rapid disease transmission.

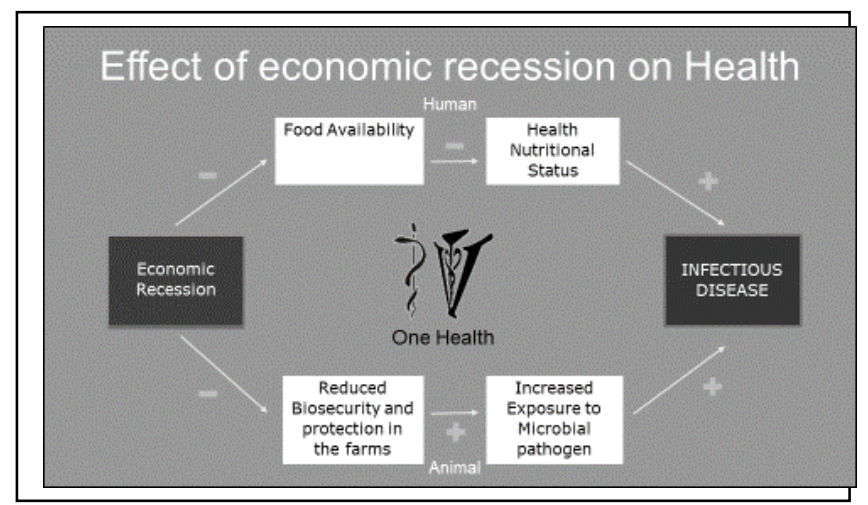

Fig. 2. The graphical representation of a recession impact on health in the long run.

The economic recession on health can be seen in the context of one health perspective in the long-run effect, as shown in Fig. 2. As a logical framework, figure 2 specifically pinpointing the linkage between economic activities with a health condition in a nation. The initial assumption is that the economic recession decreases farm capability to manage plant and animal production 
appropriately. It will lead to two pathways of reasoning. First, the recession is limited farm capability in production. Therefore, many farms will reduce their input. Consequently, the food supply is decreasing, and at the same time, the food price is increasing. It will reduce food availability for the whole nation due to limited supply and limited access. As a result, the impact on humans is lower health and nutritional status- the lower health condition on human increases infectious disease [1]. Second, as the farm capability is decreasing, limited animal farm management is applied. It will reduce farm biosecurity and the protection in the farms [10]. Eventually, limited biosecurity and protection will lead to an increase in exposure to microbial pathogens. The exposure gives a suitable environment for microbial pathogens to grow. The environment leads to a higher risk of mortality in the animal. The mortality will increase the number of infectious disease incidents.

In general, the hypothesis of a recession's impact on infectious diseases is a clear idea and proven by previous studies [1,9]. The lesser capability of a farm to manage animal production increases the possibility of newly emerging animal diseases. Impoverished settings caused by the recession are affecting many farms in developing countries across the world. These farmers are considered as hotspots for these emerging diseases. Several epidemics of diseases like Avian Influenza, Swine Influenza, circulate between farms are uncontrollable under the recession. On the other hand, animal diseases cause major economic loss through and less efficient production shown by mortality, reduced productivity, lower fertility, condemned products, and restricted access to potential markets. Furthermore, many consumers consume less healthy animal products $[10$, 11]. As a result, less productive farm impacts their ability to recover quickly. Since the farm level is at the micro-level or economics organization, the aggregate impacts of the farm industry are depicted in the mezzo level. In macroeconomics, the farm industry is connected to other sectors. Therefore, the economic problem in the farm industry will be transmitted to the other industries. It will lead to depression economics..

\section{NEXT: DISEASE CONTROL IS IMPORTANT TO RECOVER ECONOMY}

Since the business cycle approach shows the cyclical relationship, the disease control measure is becoming critical to shift the recession phase to the recovery phase. Since the link between economy to epidemiology is now reverse into epidemiology to economy. Controlling and intervene in disease risk in epidemiology are the key factor to ensure economic factors to become more stable and efficient to reach a desired economic scale of production. It will counterbalance the recession phase and make progress for new investment opportunities.

In this proposed approach, we attempt to design hypothesis research that examines: first, the emerging disease caused by the economic recession; second, disease control measure and its impact on health as an important link to recover business cycle. This paper proposes the application of micro-mezzo-macroeconomics as a concept to describe a clear understanding of the organization of the economic activities with regards to policy responses [2]. This approach will identify the factors that involve economic motives for intervention based on the economic level interaction. It will accomplish our main intention to examine the business cycle and its links to health and disease control. We believe the approach will give groundwork for the government to set up a further plan.

We believe that for the first time, the analysis will be able to link the economic and its business cycle with disease control in Indonesia. Differently from previous economic studies, this approach contributed to a novel macroeconomic strategy in relation to one health. Lastly, the key insights of business cycle will give a description of one health and responds to disease risk. It can be completed by further economic analysis. Since people take account of possible disease threats, it is important to analyze the spread of disease as a function of the costs and benefits of disease risk management.

\section{CONCLUSION}

The expected results from the proposed approach are threefold. First, the approach gives insight into the interaction between economic recession and animal health. Second, the interaction is between macroeconomic and microeconomic via mezzo-economics could provide a general map for economic interaction. Third, circular interaction between economic and animal health diseases shows that disease control is an essential in supporting economic recovery..

\section{REFERENCES}

[1] C. Perrings et al., "Merging economics and epidemiology to improve the prediction and management of infectious disease," EcoHealth, vol. 11, no. 4, pp. 464-475, 2014.

[2] K. Dopfer, J. Foster, and J. Potts, "Micro-meso-macro," Journal of evolutionary economics, vol. 14, no. 3, pp. 263-279, 2004.

[3] T. u. Puu and I. Sushko, Business cycle dynamics. Springer, 2006.

[4] D. E. Sichel, "Inventories and the Three Phases of the Business Cycle," Journal of Business \& Economic Statistics, vol. 12, no. 3, pp. 269-277, 1994/07/01 1994.

[5] B. C. Greenwald and J. E. Stiglitz, "Keynesian, new Keynesian, and new classical economics," ed: National Bureau of Economic Research Cambridge, Mass., USA, 1987.

[6] N. G. Mankiw, "Real business cycles: A new Keynesian perspective," Journal of economic perspectives, vol. 3, no. 3, pp. 7990, 1989.

[7] C. I. Plosser, "Understanding real business cycles," Journal of Economic Perspectives, vol. 3, no. 3, pp. 51-77, 1989.

[8] R. W. Dimand and D. Laidler, "Macroeconomics with and without Keynes," History of Economics Review, vol. 24, no. 1, pp. 23-42, 1995.

[9] M. Suhrcke et al., "The impact of economic crises on communicable disease transmission and control: a systematic review of the evidence," PloS one, vol. 6, no. 6, p. e20724, 2011.

[10] D. Indrawan, K. M. Rich, P. van Horne, A. Daryanto, and H. Hogeveen, "Linking supply chain governance and biosecurity in the context of HPAI control in Western Java: a value chain perspective," Frontiers in veterinary science, vol. 5, 2018.

[11] D. Indrawan, G. Tacken, and H. Hogeveen, "What drives the choice of poultry market channel and the change of purchase behavior due to highly pathogenic avian influenza outbreaks?," Poultry science, vol. 97, no. 10, pp. 3652-3660, 2018. 